Case report
Department of Genito-Urinary Medicine, Derriford Hospital, Plymouth S D K Baguley

Department of Histopathology M E F Smith

Correspondence to: Dr Baguley, Clinic 34, Royal Darwin Hospital, Darwin, Northern Territory, Australia stevebaguley@bigfoot.com

Accepted for publication 8 March 2001

\title{
Syringomata: an unusual differential diagnosis of anogenital warts
}

\author{
Stephen D K Baguley, Mark E F Smith
}

A 19 year old woman presented to the genitourinary medicine clinic complaining of numerous lumps on her lower abdomen, vulva, and infraorbital region which had been present for 7 years. The lesions were usually asymptomatic but occasionally itched. The patient had attended her general practitioner and been told that they were warts, but treatment with podophyllin had had no effect.

The woman was in good health, was taking the combined oral contraceptive pill and had

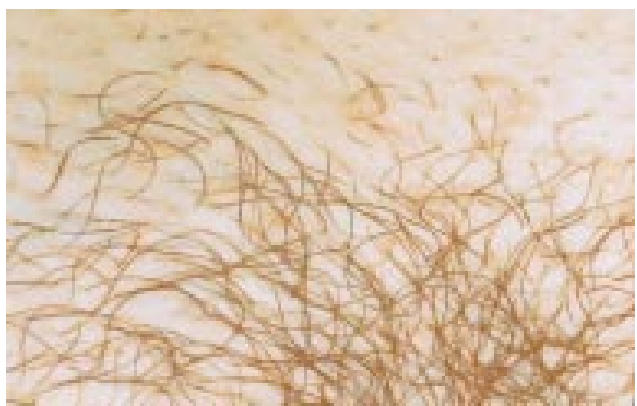

Figure 1 Numerous syringomata at margin of pubic hair.

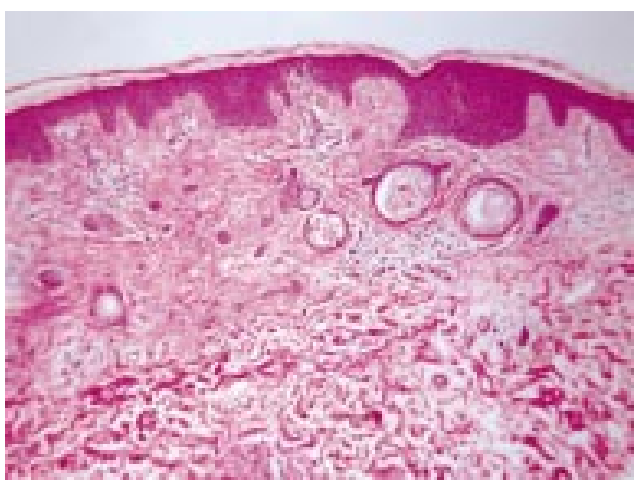

Figure 2 Low power micrograph of skin showing syringoma. Irregular glands, some with comma-shaped profiles, are present in the upper dermis associated with dense, fibrous stroma. one long term partner who was well. There was no family history of similar lesions.

On examination she had about 200 irregular, yellowish-brown papules extending from her navel to labia majora (fig 1). The lesions were 2-6 $\mathrm{mm}$ in diameter. The diagnosis was unclear so a punch biopsy was taken from one of the lesions. Histology demonstrated numerous small ducts embedded in fibrous tissue and located in the papillary dermis (fig 2). The ducts were lined by two rows of epithelial cells and many showed a comma-shaped profile. The appearances were diagnostic of a benign syringoma. ${ }^{1}$

Syringomata are benign adnexal tumours which show eccrine sweat gland differentiation and look superficially quite similar to warts although they have a slightly greasy texture. They usually develop at puberty and there is sometimes a family history. The commonest areas of involvement are the eyelids, upper arms, and abdomen. Vulval syringomata are rare although lesions have been described on the labia majora, ${ }^{2}$ labia minora, and the inner thighs. The lesions are usually multiple and bilaterally symmetrical. Malignant syringomata have been reported but are thought to arise de novo rather than from transformation of a benign lesion.

Treatment of benign syringomata is only necessary for aesthetic reasons. A variety of destructive methods have been employed, including trichloroacetic acid and laser ablation. The most successful therapy appears to be diathermy and this is the method being used in this patient.

Funding: none

Contributors: SB mane the patient. MS made the diagnosis and supplied the photomicrograph.

1 Buckley $\mathrm{CH}$, Fox $\mathrm{H}$. Epithelial tumours of the vulva. In: Ridley, ed. The vulva. Edinburgh: Churchill Livingstone, 1988.

2 Brown SM, Freeman RG. Syringoma limited to the vulva. Arch Dermatol 1971;104:331. 